\title{
A year in the life of a central California kelp forest: physical and biological insights into biogeochemical variability
}

\author{
David A. Koweek ${ }^{1, \text { a }}$, Kerry J. Nickols ${ }^{2,3}$, Paul R. Leary ${ }^{2}$, Steve Y. Litvin ${ }^{2}$, Tom W. Bell ${ }^{4}$, Timothy Luthin ${ }^{1}$, \\ Sarah Lummis $^{2, b}$, David A. Mucciarone ${ }^{1}$, and Robert B. Dunbar ${ }^{1}$ \\ ${ }^{1}$ Department of Earth System Science, Stanford University, Stanford, CA 94305, USA \\ ${ }^{2}$ Department of Biology, Hopkins Marine Station, Stanford University, Pacific Grove, CA 93950, USA \\ ${ }^{3}$ School of Natural Sciences, California State University Monterey Bay, Seaside, CA 93955, USA \\ ${ }^{4}$ Earth Research Institute, University of California, Santa Barbara, CA 93106, USA \\ apresent address: Department of Global Ecology, Carnegie Institution for Science, Stanford, CA 94305, USA \\ b present address: Department of Ecology and Evolutionary Biology, University of California Santa Cruz, \\ Santa Cruz, CA 95060, USA
}

Correspondence to: David A. Koweek (dkoweek@carnegiescience.edu)

Received: 27 August 2016 - Published in Biogeosciences Discuss.: 31 August 2016

Revised: 16 December 2016 - Accepted: 16 December 2016 - Published: 5 January 2017

\begin{abstract}
Kelp forests are among the world's most productive marine ecosystems, yet little is known about their biogeochemistry. This study presents a 14-month time series (July 2013-August 2014) of surface and benthic dissolved inorganic carbon and total alkalinity measurements, along with accompanying hydrographic measurements, from six locations within a central California kelp forest. We present ranges and patterns of variability in carbonate chemistry, including $\mathrm{pH}$ (7.70-8.33), $\mathrm{pCO}_{2}$ (172-952 $\mu$ atm), and the aragonite saturation state, $\Omega_{\mathrm{Ar}}(0.94-3.91)$. Surface-tobottom gradients in $\mathrm{CO}_{2}$ system chemistry were as large as the spatial gradients throughout the bottom of the kelp forest. Dissolved inorganic carbon variability was the main driver of the observed $\mathrm{CO}_{2}$ system variability. The majority of spatial variability in the kelp forest can be explained by advection of cold, dense high- $\mathrm{CO}_{2}$ waters into the bottom of the kelp forest, with deeper sites experiencing high$\mathrm{CO}_{2}$ conditions more frequently. Despite the strong imprint of advection on the biogeochemical variability of the kelp forest, surface waters were undersaturated with $\mathrm{CO}_{2}$ in the spring through fall, indicative of the strong role of photosynthesis on biogeochemical variability. We emphasize the importance of spatially distributed measurements for developing a process-based understanding of kelp forest ecosystem function in a changing climate.
\end{abstract}

\section{Introduction}

Kelp forests are found along rocky coastlines in temperateto-subpolar coastal regions throughout the world's oceans. Kelp is an important foundation species that support diverse biological communities, including invertebrates, fishes, and marine mammals through their creation of complex, threedimensional biological habitat and the provisioning of carbon and nutrients which magnify secondary production in the coastal zone (Steneck et al., 2002). Kelp forest ecology has been a focus of study since the early twentieth century, largely due to its importance as an ecologically rich habitat (as reviewed in Graham et al., 2007).

Kelp (including Ecklonia spp., Laminaria spp., and Macrocystis spp.) forests are among the most productive marine ecosystems (Mann, 1982), with linear extension rates of kelp fronds that can range from 2 to $14 \mathrm{~cm} \mathrm{~d}^{-1}$ (Graham et al., 2007). Productivity rates vary depending upon the geographic region and species of consideration but generally range from 600 to $1500 \mathrm{~g} \mathrm{C} \mathrm{m}^{-2} \mathrm{yr}^{-1}$ (Mann, 1982), although they have been documented to reach up to $3400 \mathrm{~g} \mathrm{C} \mathrm{m}^{-2} \mathrm{yr}^{-1}$ (Jackson, 1977). The high productivity in kelp forests impacts the chemical properties of the surrounding water through the uptake and release of dissolved inorganic carbon (DIC) and dissolved nutrients (nitrate and phosphate). Calcification and dissolution of kelp-associated 
organisms, especially shelled invertebrates, modify the water chemistry through the uptake and release of carbonate and bicarbonate ions, which modify the total alkalinity (TA) and DIC. Air-sea gas exchange further modifies the DIC through exchange of $\mathrm{CO}_{2}$. In addition, in the upwelling zones that support kelp forests, carbon system chemistry undergoes large fluctuations due to highly dynamic regional-scale advection of high- $\mathrm{CO}_{2}$ deep waters (Booth et al., 2012). The combination of biological and physical processes can lead to large biogeochemical variability in kelp forests. For example, $\mathrm{pH}$ (NBS scale) values of up to 9.1 have been recorded in one subantarctic kelp forest while matching samples taken directly outside the kelp bed had pH (NBS scale) of 8.3 (Delille et al., 2000). In southern California, Frieder et al. (2012) measured $\mathrm{pH}$ (total scale) values as low as 7.7 (corresponding to $p \mathrm{CO}_{2}$ of $\left.1000 \mu \mathrm{atm}\right)$.

Despite the recognized importance of kelp as a foundation species and biogeochemical agent, little attention has been paid to biogeochemical variability in kelp forests (see Delille et al., 2000, 2009; Frieder et al., 2012; Hofmann et al., 2011; Kapsenberg and Hofmann, 2016; Takeshita et al., 2015). Of the few studies that have addressed kelp forest biogeochemistry, most have focused on $\mathrm{pH}$ measurements in southern California (Frieder et al., 2012; Hofmann et al., 2011; Kapsenberg and Hofmann, 2016; Takeshita et al., 2015), which - while certainly useful - does not provide complete information about the $\mathrm{CO}_{2}$ system chemistry in kelp forests. The lack of geographically distributed biogeochemical observations in kelp forests may be due to the difficulties of long-term field observations and/or the lack of automated instrumentation and procedures for making continuous, high-quality biogeochemical measurements until recently (Bresnahan et al., 2014). Our limited understanding of kelp forest $\mathrm{CO}_{2}$ system chemistry inhibits our ability to establish biogeochemical baselines as well as to forecast how kelp forest communities may interact with changes in water chemistry from local stressors, such as runoff and sedimentation, as well as from global stressors, such as climate change and ocean acidification (OA).

The genus Macrocystis (order Laminariales), or giant kelp, is the most widely distributed kelp genus in the world. Found in both the Northern Hemisphere and the Southern Hemisphere, it dominates kelp assemblages in southern and central California (Graham et al., 2007). We present results from a 14-month biogeochemical study in a central California Macrocystis pyrifera-dominated kelp forest. Our goals were to quantify temporal and spatial carbon system biogeochemical variability in a kelp forest over an annual cycle and investigate the responsible mechanisms.

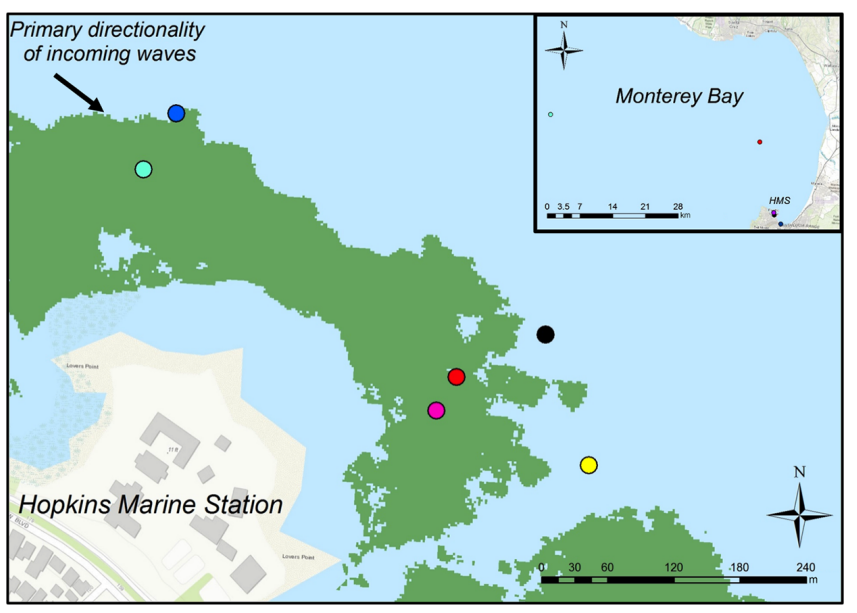

Figure 1. Study site: kelp forest offshore of Hopkins Marine Station. Green shows historical average kelp canopy extent. Site names are as follows: Protected Offshore (Pro Off; black), Protected Middle (Pro Mid; red), Protected Inside (Pro Inn; magenta), Kelp Forest Array (KFA; yellow), Exposed Offshore (Exp Off; blue), and Exposed Middle (Exp Mid; cyan). Inset shows Monterey Bay with color dots corresponding to the data buoys shown in Fig. S1.

\section{Methods}

\subsection{Study site}

Our study site is located along the eastern side of the Monterey Peninsula in the central portion of the California Current Large Marine Ecosystem (Fig. 1) (Checkley and Barth, 2009). This region is characterized by seasonal upwelling conditions driven by increased northwesterly winds from $\sim$ March to September (Checkley and Barth, 2009) (Fig. S1). Although much of the Monterey Peninsula is protected from the stronger alongshore winds and associated surface conditions experienced by the nearby exposed coastline and northern Monterey Bay, it still experiences cross-shore transport associated with upwelling (Woodson, 2013). Advection of upwelled waters and the local topography also facilitate the propagation of internal bores into southern Monterey Bay, which act as an additional mechanism for introducing dense, high- $\mathrm{CO}_{2}$ deep ocean water into nearshore habitats and driving variability in $\mathrm{CO}_{2}$ chemistry at short temporal scales (Booth et al., 2012; Walter et al., 2014).

The kelp forest is located in the Lovers Point-Julia Platt State Marine Reserve, directly offshore of Hopkins Marine Station along the wave-protected side of the Monterey Peninsula (Fig. 1). The reserve was created in 2007 as part of the network of central California marine-protected areas designated under the California Marine Life Protection Act (Lovers Point-Julia Platt State Marine Reserve Fact Sheet, 2016). The kelp forest in the Lovers Point-Julia Platt State Marine Reserve has been protected since 1931, originally as the Hopkins Marine Life Refuge. Due to its protected status, 
the reserve serves as a natural laboratory to investigate the biogeochemistry of a central California kelp forest featuring low levels of human disturbance.

Within this kelp forest we selected six sites that span gradients in wave exposure, depth, and proximity to the kelp bed (Fig. 1; referenced as Protected Inside, Protected Middle, Protected Offshore, Exposed Middle, Exposed Offshore, and KFA). Sites inside the kelp bed ranged from 7.5 to $11 \mathrm{~m}$, and sites just outside the kelp bed ranged from 13.5 to $16 \mathrm{~m}$ depth. The site inside the kelp bed on the wave-exposed side (Exposed Middle) was slightly deeper than sites on the protected side because we were unable to reliably sample the wave-exposed side of the kelp bed in shallower waters for operational reasons. The six sites ranged from 130 to $270 \mathrm{~m}$ offshore (Table 1). Sites along the transect on the western side of the kelp forest experienced greater wave exposure than sites on the protected side due to the northwestern directionality of incoming waves (Fig. S2). Both the wave-exposed and waveprotected transects were oriented perpendicular to the kelp forest in order to sample within and just outside of the kelp bed. The KFA site (located above the main node of the Kelp Forest Array, an underwater cabled observatory) was located east of the protected transect and served as a kelp-free control site, although it was close enough to the kelp forest to be influenced by the advection of chemically modified water from the kelp forest.

\subsection{Water sampling}

We sampled biogeochemical and hydrographic properties at the six study sites at approximately weekly intervals spanning July 2013-August 2014. Samples were collected between 09:00 and 12:00 local time in order to minimize any potential confounding influence of the diel cycle on the weekly-scale biogeochemical variability. We collected water samples for DIC and TA analysis at $1 \mathrm{~m}$ below the surface $(1 \mathrm{~m} \mathrm{~b} . s$.) and $1 \mathrm{~m}$ above the bottom $(1 \mathrm{~m}$ a.b. $)$ using $1.7 \mathrm{~L}$ Niskin bottles at all six sites (Fig. 1). We chose these depths for water sampling in order to sample where most of the kelp biomass resided ( $1 \mathrm{mb}$ b.s.) and where most kelp forest inhabitants lived (1 $\mathrm{m}$ a.b.). Water was sampled from the Niskin bottle into a $30 \mathrm{~mL}$ bottle for DIC and a $300 \mathrm{~mL}$ bottle for TA. Samples were immediately preserved by addition of $30 \mu \mathrm{L}$ (DIC) or $300 \mu \mathrm{L}$ (TA) saturated mercuric chloride solution $\left(\mathrm{HgCl}_{2}\right)$ upon collection from Niskin bottles. Samples were typically analyzed within 1-2 weeks of collection. We conducted simultaneous CTD hydrocasts (SBE 19plus, Sea-Bird Electronics, Inc.) at each station to characterize the vertical water column structure and provide in situ temperature and salinity necessary for carbon system calculations (see below).

We used CTD hydrocasts to quantify water column stratification by determining the density difference between the upper $2 \mathrm{~m}$ and the bottom $2 \mathrm{~m}$.

$\Delta \rho=\bar{\rho}_{\text {bottom }}-\bar{\rho}_{\text {surface }}$,

where $\Delta \rho$ is in $\mathrm{kg} \mathrm{m}^{-3}, \bar{\rho}_{\text {bottom }}$ is the average density across the bottom $2 \mathrm{~m}$ of the water column, and $\bar{\rho}_{\text {surface }}$ is the average density across the top $2 \mathrm{~m}$ of the water column. We chose to average across $2 \mathrm{~m}$ at both the top and bottom sites in order to span the depth of water sample collection $(1 \mathrm{~m}$ b.s. and $1 \mathrm{~m}$ a.b.).

Sample sets from July and August 2013 were collected over 2 days, with the samples from the protected transect typically collected a day before the samples from the exposed transect and the KFA site. We include these first 2 months of the time series when presenting the data as time series, but in order to avoid confounding variability from sampling on different days, any of the analyses presented here which require comparisons between the sites are limited to the period of September 2013-August 2014, when samples were all collected within approximately $90 \mathrm{~min}$ of one another.

\subsection{Water chemistry}

Water samples were analyzed at the Stanford University Stable Isotope Biogeochemistry Laboratory (Stanford, California, USA). DIC was measured with a custom-built sample acidification and delivery system coupled to an infrared gas analyzer (LI-COR 7000) described in Long et al. (2011). The instrument was calibrated prior to each use and monitored throughout run sequences with Certified Reference Materials (CRM) provided by A. Dickson (Scripps Institution of Oceanography). Instrumental precision from 467 CRM analyses over the length of the study was $\pm 1.9 \mu \mathrm{mol} \mathrm{kg}{ }^{-1}$ (1 SD). Immediate duplicate analyses of samples usually yielded instrumental precision of $1-2 \mu \mathrm{mol} \mathrm{kg}{ }^{-1}$.

Samples for TA measurements were pre-filtered through a $0.45 \mu \mathrm{m}$ filter before being analyzed on a Metrohm 855 Robotic Titrosampler (Metrohm USA, Inc.) using certified $0.1 \mathrm{~N} \mathrm{HCl}$ provided by A. Dickson (Scripps Institution of Oceanography). Total alkalinity calculations from raw titration data follow Dickson et al. (2003). Sample runs were corrected based on the offset between the measured and certified value for CRMs, resulting in an accuracy that was always better than $1.7 \%$ and was better than $0.5 \%$ on $79 \%$ of analyses. Instrumental precision from 272 CRM analyses over the duration of this study was $\pm 2.2 \mu \mathrm{mol} \mathrm{kg}-1$ (1 SD). Immediate duplicate analyses of samples usually yielded instrumental precision of $1-2 \mu \mathrm{mol} \mathrm{kg}-1$.

\subsection{Carbon system calculations}

We calculated $\mathrm{pH}, p \mathrm{CO}_{2}$, and $\Omega_{\text {Aragonite }}\left(\Omega_{\mathrm{Ar}}\right)$ in CO2SYS (van Heuven et al., 2011) using DIC, TA, in situ temperature, and salinity data. We assumed silica concentrations of $3 \mu \mathrm{mol} \mathrm{kg}{ }^{-1}$ (Brzezinski et al., 2003) and phosphate concentrations of 0.5 and $1 \mu \mathrm{mol} \mathrm{kg}-1$ for the surface and bot- 
Table 1. Study site characteristics. Distance from shore measured from the closest perpendicular location.

\begin{tabular}{lrrrr}
\hline Site & $\begin{array}{r}\text { Latitude } \\
\left({ }^{\circ} \mathrm{N}\right)\end{array}$ & $\begin{array}{r}\text { Longitude } \\
\left({ }^{\circ} \mathrm{W}\right)\end{array}$ & $\begin{array}{r}\text { Depth } \\
(\mathrm{m})\end{array}$ & $\begin{array}{r}\text { Distance from } \\
\text { shore }(\mathrm{m})\end{array}$ \\
\hline Protected Offshore & 36.621983 & 121.900883 & 16 & 250 \\
Protected Middle & 36.6216 & 121.90176 & 9 & 160 \\
Protected Inside & 36.62132 & 121.90195 & 7.5 & 130 \\
KFA & 36.62363 & 121.90473 & 14 & 270 \\
Exposed Offshore & 36.62316 & 121.90503 & 13.5 & 200 \\
Exposed Middle & 36.62093889 & 121.9003806 & 11 & 160 \\
\hline
\end{tabular}

tom, respectively, based on measurements made in FebruaryAugust 2014 (see data file in the Supplement for original phosphate data). We used the carbonate system dissociation constants from Mehrbach et al. (1973) as re-fit by Dickson and Millero (1987), and $\mathrm{K}_{\mathrm{SO}_{4}}$ for the bisulfate ion from Dickson (1990). pH data are reported here on the total hydrogen ion scale at in situ temperature.

We estimated error for $\mathrm{pH}, p \mathrm{CO}_{2}$, and $\Omega_{\mathrm{Ar}}$ calculations using a Monte Carlo approach. We randomly selected 10 samples in the data set, used the above-listed instrumental precisions for DIC and TA, assumed no error on the temperature and salinity measurements, and performed 1000 iterations on each of the 10 samples. We did not consider error on the carbonate system equilibrium constants. The Monte Carlo simulations resulted in simulated distributions of $\mathrm{pH}$, $p \mathrm{CO}_{2}$, and $\Omega_{\mathrm{Ar}}$ for each of the 10 randomly selected samples in the data set. We calculated the standard deviation of each distribution. The maximum standard deviations of the set of 10 simulated distributions of $\mathrm{pH}, p \mathrm{CO}_{2}$, and $\Omega_{\mathrm{Ar}}$ are 0.01 units, $20 \mu \mathrm{atm}$, and 0.03 units, respectively. We consider these error estimates to be conservative since they are the maximum instead of average values.

We quantified the effects of TA, DIC, temperature, and salinity on the observed vertical differences $\left(\Delta y_{\text {Top-Bottom }}\right)$ in $\mathrm{pH}, p \mathrm{CO}_{2}$, and $\Omega_{\mathrm{Ar}}$, using a first-order Taylor series budget following Hauri et al. (2013):

$$
\begin{aligned}
\Delta y_{\text {Top-Bottom }} & =\frac{\partial y}{\partial T} \Delta T_{T-B}+\frac{\partial y}{\partial S} \Delta S_{T-B}+\frac{\partial y}{\partial \mathrm{TA}} \Delta \mathrm{TA}_{T-B} \\
& +\frac{\partial y}{\partial \mathrm{DIC}} \Delta \mathrm{DIC}_{T-B}
\end{aligned}
$$

where $y$ is $\mathrm{pH}, p \mathrm{CO}_{2}$, or $\Omega_{\mathrm{Ar}}$ and the terms on the right-hand side of the equation account for the effects of temperature, salinity, TA, and DIC, respectively. The partial derivatives $\left(\frac{\partial y}{\partial T}, \frac{\partial y}{\partial S}, \frac{\partial y}{\partial \mathrm{TA}}, \frac{\partial y}{\partial \mathrm{DIC}}\right)$ were estimated numerically in CO2SYS centered at the mean values of temperature, salinity, TA, and DIC across the entire data set (Table S1 in the Supplement).

\subsection{Satellite-derived kelp canopy biomass estimates}

We estimated giant kelp canopy biomass from July 2013 to August 2014 using multispectral Landsat 7 Enhanced Thematic Mapper and Landsat 8 Operational Land Imager im- agery (Bell et al., 2015a; Cavanaugh et al., 2011). Briefly, each Landsat image was atmospherically corrected using 50 temporally stable pseudo-invariant targets to standardize radiometric signals across dates. The proportion of kelp canopy in each $30 \mathrm{~m} \times 30 \mathrm{~m}$ pixel was determined using multiple end-member spectral mixing analysis (Roberts et al., 1998), in which each pixel was modeled as a combination of 1 static kelp end-member and 30 seawater end-members, which were unique to each image. Kelp canopy biomass and $95 \%$ confidence intervals were estimated by comparing diver estimated canopy biomass and Landsat pixel kelp fraction using a reduced major axis linear regression (MATLAB function 1sqfitgm; detailed methods in Cavanaugh et al., 2011).

\subsection{Current velocity time series}

Water column velocity was measured continuously near the exposed and protected sites in the middle of the kelp forest using bottom-mounted acoustic Doppler current profilers (RD Instruments, $1200 \mathrm{kHz}$ ). The instruments recorded ensemble averaged velocities every $3 \mathrm{~min}$ in $0.5 \mathrm{~m}$ bins extending from $\sim 1.5 \mathrm{~m}$ above the bottom to $\sim 1.5 \mathrm{~m}$ below the surface. The instrument on the protected side of the kelp forest was deployed throughout this study, while the instrument on the exposed side of the kelp forest was deployed through December 2013.

\section{Results}

\subsection{Kelp canopy biomass}

Satellite-estimated kelp canopy biomass displayed a strong seasonal cycle, consistent with previous observations of the strong seasonality of kelp canopy biomass in central California (Bell et al., 2015b; Reed et al., 2011). Canopy biomass increased throughout spring, reached a maximum during the summer months, and decreased throughout the fall, reaching minimum values in the winter. The timing of kelp growth, senescence, and canopy biomass range were generally consistent between the wave-protected and wave-exposed sides of the kelp forest (Fig. 2a). However, canopy biomass on the exposed side began to decline slightly before canopy biomass on the protected side in summer 2014, leading to a decou- 

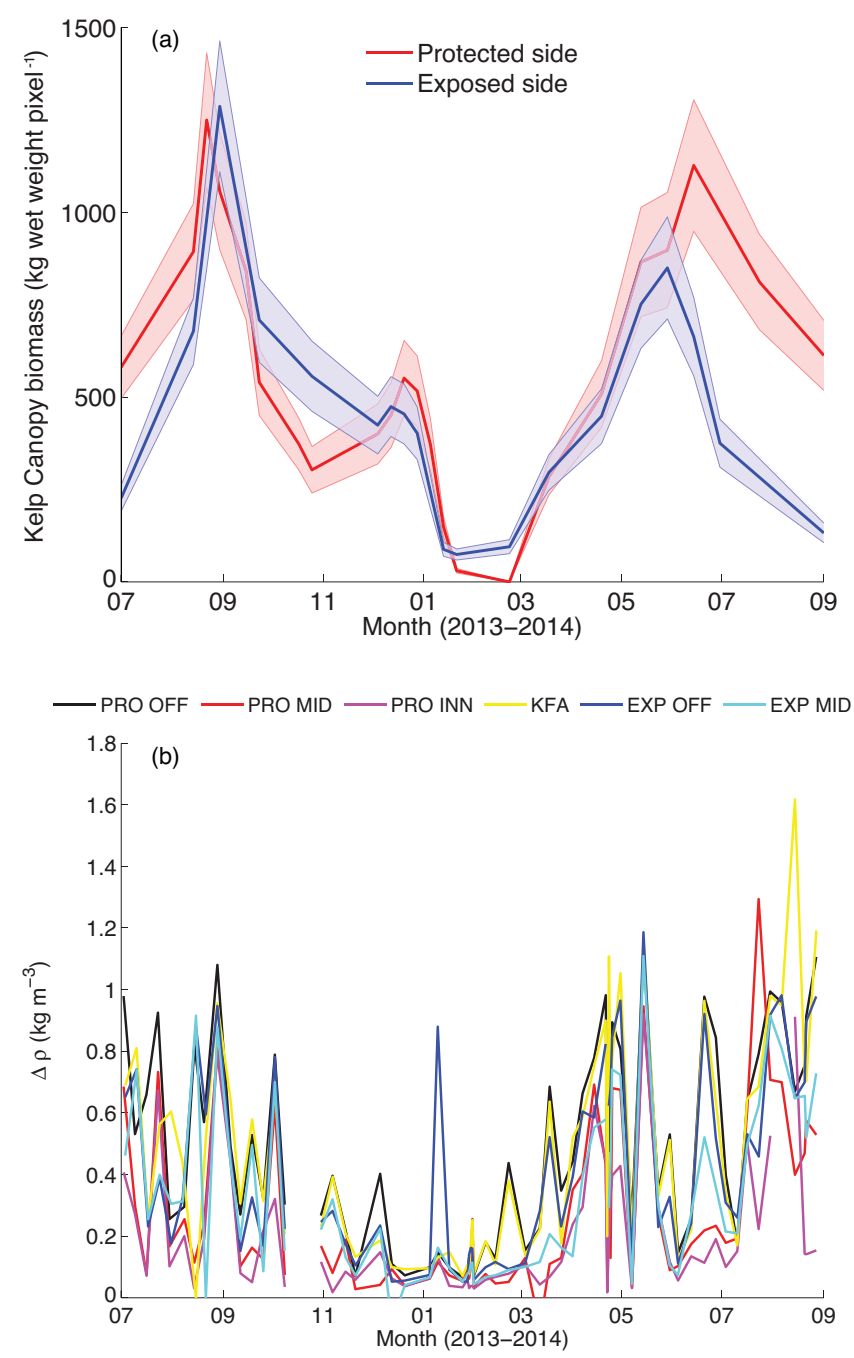

Figure 2. Time series of (a) satellite-derived kelp canopy biomass per $30 \mathrm{~m} \times 30 \mathrm{~m}$ satellite pixel for the protected and exposed sides, and (b) $\Delta \rho$ for all six sites. The shaded bars in (a) show the $95 \%$ confidence interval of the kelp canopy biomass estimate.

pling of canopy biomass between the two sides from June to September 2014.

\subsection{Water column structure}

The kelp forest water column was strongly influenced by seasonal variations in surface and bottom water temperature. We use the protected side transect, which spans the largest range in site depths, to examine these processes in detail (Fig. 3). During the spring, cold $\left(\sim 10^{\circ} \mathrm{C}\right)$, dense bottom water was advected into the deepest kelp forest site (Protected Offshore), causing water column temperature differences of up to $4{ }^{\circ} \mathrm{C}$ across $16 \mathrm{~m}$ depth. This cold bottom water did not reach further inshore along the bottom of the shallower, inwards Protected Middle and Protected Inside sites (Fig. 3). Surface heating during summer 2014 resulted in uniformly

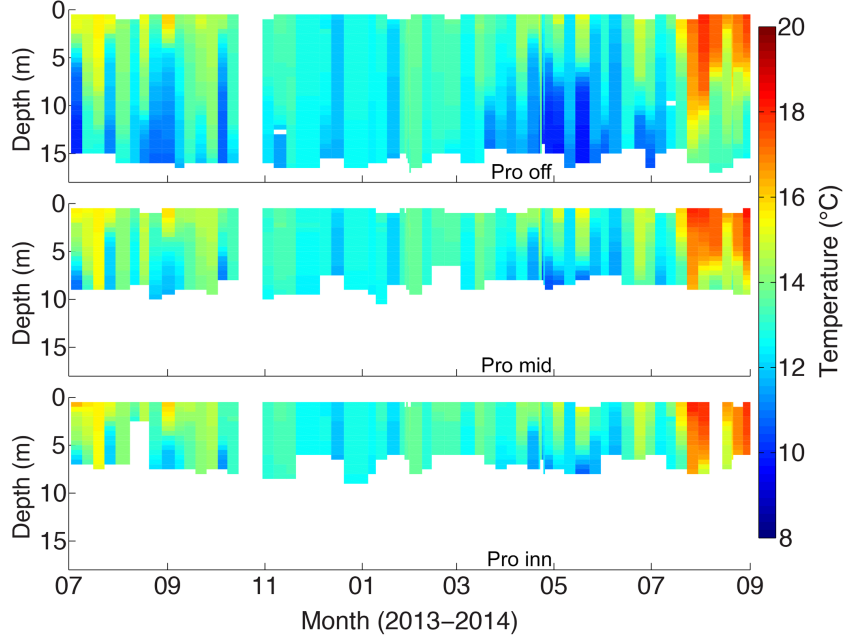

Figure 3. Depth-resolved temperature profiles along the protected transect throughout the 14-month time series. White spaces, including October 2013 and August 2014, are missing data due to the CTD not recording or poor data removed during quality control.

warm surface waters $\left(\sim 16-18^{\circ} \mathrm{C}\right)$ across the sites along the protected transect. Reduced stratification at the shallower Protected Inside site allowed warmer surface waters to mix downwards, which resulted in a nearly isothermal water column, whereas temperature stratification was maintained in the deeper Protected Offshore site. Salinity showed a seasonal cycle across all three sites of the protected transect with higher salinity during upwelling season, where values ranged from $\sim 33.6$ to 34 , as compared to less saline winter months, where salinity ranged from 33 to 33.6 (Fig. S3). However, there was little evidence for depth-dependent variation in salinity, suggesting that temperature was the dominant control on water column stratification. These patterns were similar across all sites.

Water column stratification, as quantified by $\Delta \rho$, was greatest and most variable from the start of upwelling season throughout the fall where $\Delta \rho$ exceeded $1 \mathrm{~kg} \mathrm{~m}^{-3}$, with strong site-to-site variability (e.g., June-August 2014; Fig. 2b). Throughout most of the year, $\Delta \rho$ was greatest and most variable at the Protected Offshore, KFA, Exposed Offshore, and Exposed Mid sites. Protected Middle and Protected Inside typically, although not always, had lower $\Delta \rho$ and less variability from week to week. All sites were minimally stratified in the winter months, as $\Delta \rho$ generally stayed below $0.4 \mathrm{~kg} \mathrm{~m}^{-3}$ and was generally less than $0.2 \mathrm{~kg} \mathrm{~m}^{-3}$ in December 2013-February 2014. Site-to-site variability was also reduced in the winter months, although there was one anomalously high stratification observation at the Exposed Offshore site in early January 2014 , where $\Delta \rho$ nearly reached $1 \mathrm{~kg} \mathrm{~m}^{-3}$. 


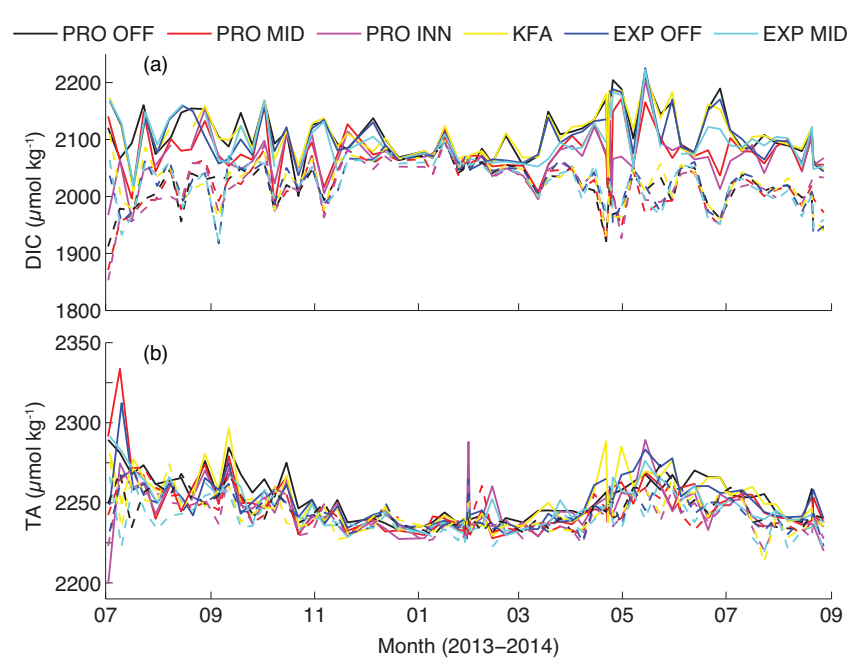

Figure 4. Time series of (a) DIC and (b) TA. Solid lines are bottom samples and dashed lines are surface samples.

\section{3 $\mathrm{CO}_{2}$ system chemistry time series}

The 14-month time series of DIC for all six sites near the surface $(1 \mathrm{mb}$.s.) and the bottom (1 ma.b.) exhibited strong week-to-week, site-to-site, and seasonal variability (Fig. 4a). Bottom DIC frequently exceeded $2100 \mu \mathrm{mol} \mathrm{kg}^{-1}$ during fall 2013 and exceeded $2200 \mu \mathrm{mol} \mathrm{kg}^{-1}$ at all sites except Protected Middle during April-May 2014. The four deepest sites typically had highest bottom DIC during the spring and summer months, although the site-to-site variability disappeared during the winter. Surface DIC concentrations were generally much more spatially homogeneous than bottom water DIC concentrations. Surface DIC reached minimum values during spring and summer months when DIC was frequently less than $2000 \mu \mathrm{mol} \mathrm{kg}-1$.

The time series of surface and bottom TA shows reduced variability compared to the DIC time series (Fig. 4b). Surface and bottom TA samples generally ranged from 2240 to $2260 \mu \mathrm{mol} \mathrm{kg}^{-1}$, with occasionally higher values observed. Unlike DIC, TA did not show any consistent surface-tobottom gradients throughout the time series. Increased TA during the upwelling season was likely due to the high nutrient content of the source waters being advected into the kelp forest.

Time series of $\mathrm{pH}, p \mathrm{CO}_{2}$, and $\Omega_{\mathrm{Ar}}$ all exhibited similar properties to the DIC time series with strong week-to-week, site-to-site, and seasonal variability (Fig. 5). Minimum $\mathrm{pH}$ values in bottom samples ranged from 7.70 to 7.79 across the six sites, and $\mathrm{pH}$ minima grouped closely to site depth, where the four deeper sites had $\mathrm{pH}$ minima which ranged from 7.70 to 7.72 , while the $\mathrm{pH}$ minimum at Protected Middle was 7.78 and the $\mathrm{pH}$ minimum at Protected Inside was 7.79 (Fig. 5a). Bottom $\Omega_{\text {Ar }}$ values exhibited similar clustering as $\mathrm{pH}$. Surface $p \mathrm{CO}_{2}$ was undersaturated with respect to the atmosphere $(<400 \mu \mathrm{atm})$ through the early fall, spring,
Table 2. Carbon system variables summary statistics aggregating all six sampling sites.

\begin{tabular}{llrrr}
\hline Variable & Top/Bottom & Minimum & Mean & Maximum \\
\hline $\mathrm{DIC}$ & Top & 1853 & 2023 & 2110 \\
$\left(\mu \mathrm{mol} \mathrm{kg}^{-1}\right)$ & Bottom & 1958 & 2093 & 2225 \\
\hline $\mathrm{TA}$ & Top & 2213 & 2243 & 2277 \\
$\left(\mu \mathrm{mol} \mathrm{kg}^{-1}\right)$ & Bottom & 2199 & 2249 & 2337 \\
\hline $\mathrm{pH}$ & Top & 7.92 & 8.08 & 8.33 \\
& Bottom & 7.70 & 7.96 & 8.21 \\
\hline$p \mathrm{CO}_{2}$ & Top & 172 & 364 & 543 \\
$(\mu \mathrm{atm})$ & Bottom & 249 & 508 & 952 \\
\hline$\Omega_{\mathrm{Ar}}$ & Top & 1.63 & 2.43 & 3.91 \\
& Bottom & 0.94 & 1.82 & 3.23 \\
\hline
\end{tabular}

and summer, although week-to-week variability resulted in periods of $p \mathrm{CO}_{2}$ saturation and supersaturation during July and August 2014 (Fig. 5b). We observed $\Omega_{\mathrm{Ar}}$ undersaturation $\left(\Omega_{\mathrm{Ar}}<1\right)$ five times: at Protected Offshore on 25 April and 14 May 2014 and at KFA, Exposed Offshore, and Exposed Middle on 14 May 2014. Table 2 provides a summary of all carbon system variable ranges.

\subsection{Surface-to-bottom variability}

The combination of maximum kelp abundance and water column stratification led to greatest carbon system variability within the kelp forest during the upwelling season ( $\sim$ MarchSeptember). Ranges in DIC along the top, along the bottom, and vertical gradients at each sampling site, exceeded $100 \mu \mathrm{mol} \mathrm{kg}^{-1}$ at this time (Fig. 6a). Winter mixing from storms and the lack of kelp canopy reduced these differences, resulting in chemical gradients which approached $0 \mu \mathrm{mol} \mathrm{kg}{ }^{-1}$. TA spatial variability was much smaller and more variable (Fig. 6b). pH, $p \mathrm{CO}_{2}$, and $\Omega_{\mathrm{Ar}}$ exhibited strong top to bottom differences as well. Vertical differences in $\mathrm{pH}$ and $\Omega_{\mathrm{Ar}}$ reached up to 0.51 and 2.25 units, respectively.

Nearly all of the surface-to-bottom variability in $\mathrm{pH}$, $p \mathrm{CO}_{2}$, and $\Omega_{\mathrm{Ar}}$ can be attributed to vertical differences in DIC using Eq. (2). The DIC contribution to the observed surface-to-bottom differences in $\mathrm{pH}, p \mathrm{CO}_{2}$, and $\Omega_{\mathrm{Ar}}$ across the six sites ranged 88-93, 82-88, and 92-97\%, respectively (Figs. 7 and S4-S6). These results are consistent with an ecosystem dominated by organic carbon metabolism (photosynthesis/respiration) as opposed to inorganic carbon metabolism (calcification/dissolution), an expected result in a kelp forest. We note that the carbon system budgets do not discriminate between local biogeochemical modification within the kelp forest and advection of offshore water.

Cold, high-DIC water observed at the bottom of the kelp forest was a major contributor to surface-to-bottom differences in DIC (Fig. 8). High-DIC water reached the deeper 


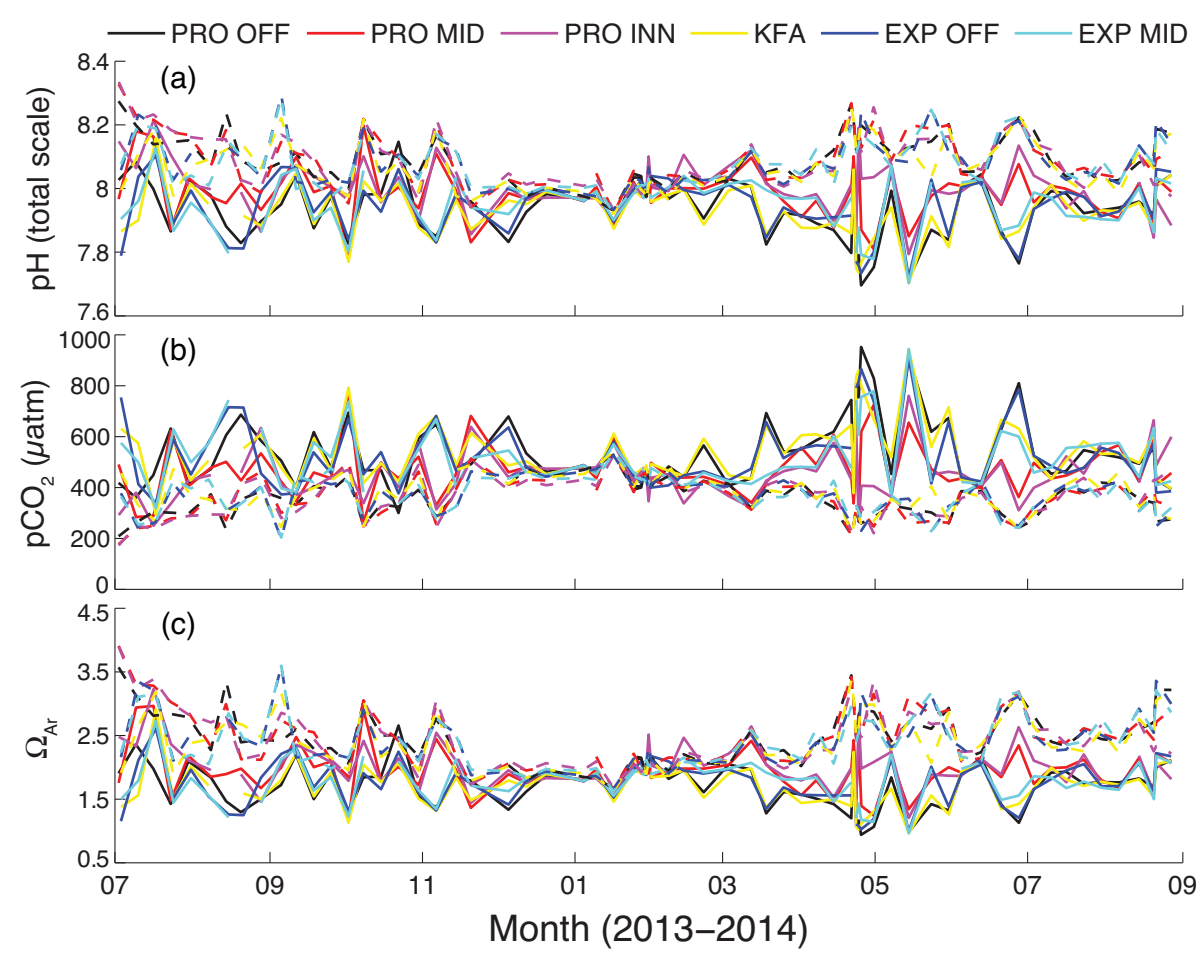

Figure 5. Time series of (a) $\mathrm{pH}$, (b) $p \mathrm{CO}_{2}$, and (c) $\Omega_{\mathrm{Ar}}$ calculated from TA and DIC measurements. Solid lines are bottom samples and dashed lines are surface samples.

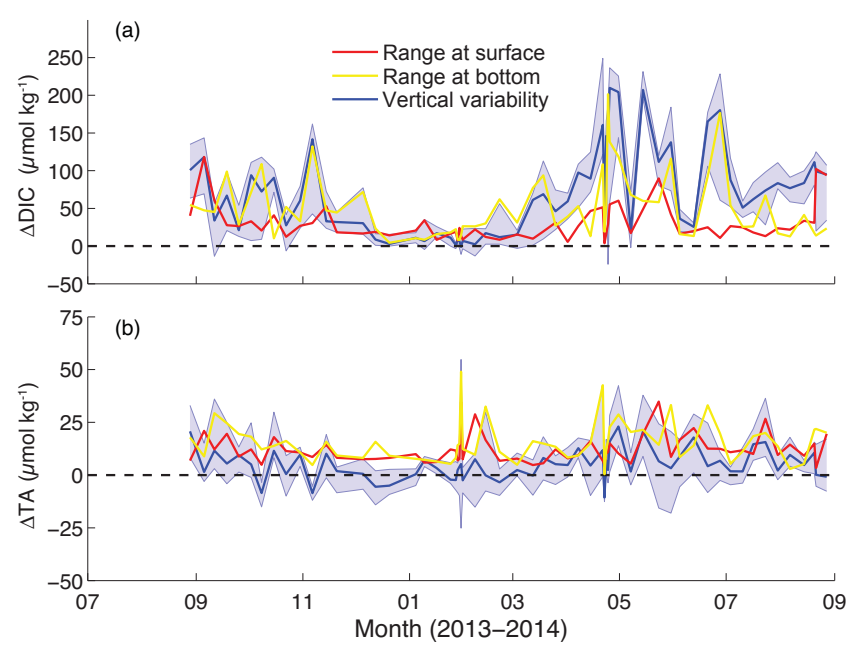

Figure 6. Variability throughout the sampling period for (a) DIC and (b) TA. The range of surface values across all six sites is shown in red, and the range of bottom values across all six sites is shown in yellow. The blue line is the median surface-to-bottom difference in DIC or TA during a given sampling day, and the blue shaded region represents the maximum and minimum vertical gradients observed on each day. Note the differences in scale between (a) and (b).

sites (Protected Offshore, KFA, Exposed Offshore, Exposed Middle) but did not frequently penetrate into the shallower sites (Protected Middle and Protected Inside). Bottom DIC accounted for 55-67\% (Pearson correlation coefficients) of observed surface-to-bottom DIC gradients in the four deeper sites (Fig. 8b) but only accounted for $39 \%$ of the observed gradient at Protected Middle and $22 \%$ of the gradient at Protected Inside. Reduced stratification at the protected shallower sites reduced water column temperature and DIC gradients (Figs. 2b, 3, and 4).

The vertical variability in $\mathrm{CO}_{2}$ system chemistry drove large variations in the Revelle factor (RF). The RF describes the nonlinear buffering capacity of seawater $\mathrm{RF}=$ $\partial \ln p \mathrm{CO}_{2} / \partial \ln$ DIC. Higher RFs indicate reduced capacity to buffer against increasing $\mathrm{CO}_{2}$ as ocean acidification progresses. RF variability within the kelp forest ranged from $\sim 9$ to 18 over the annual cycle (Fig. S7), which nearly spans the range of global surface ocean values from offshore waters (Sabine et al., 2004). Following other carbon system properties, the highest and most variable RFs were observed in the bottom waters during spring and summer. Photosynthetic uptake in the surface during upwelling months lowered RFs to between 10 and 12, with occasional values reaching below 10. Winter RFs for surface and bottom water samples converged around 12-14.

\subsection{Spatial variability}

Full-year histograms of $\Omega_{\mathrm{Ar}}$ in kelp forest bottom waters revealed significant differences (Wilcoxon rank sum test, $\alpha=0.05$ ) between the sites generally according to site depth 


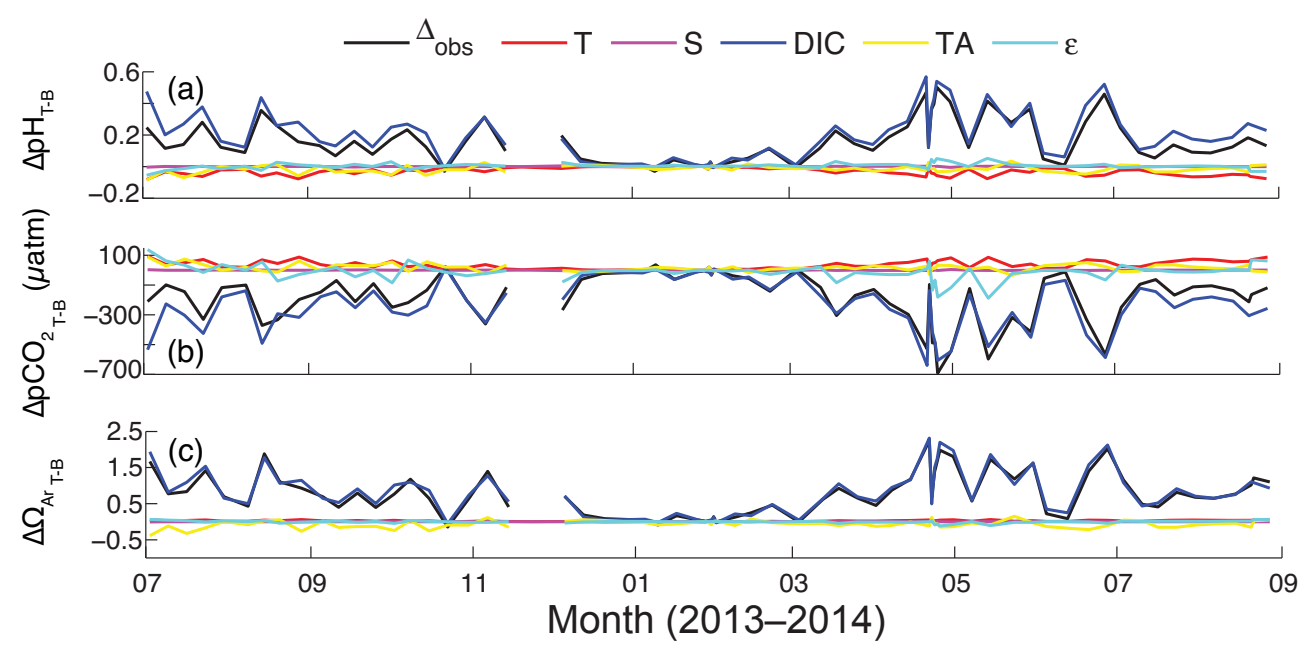

Figure 7. Observed (black) surface-to-bottom differences in (a) $\mathrm{pH}$, (b) $p \mathrm{CO}_{2}$, and (c) $\Omega_{\mathrm{Ar}}$ at the Protected Offshore site along with the calculated contributions of temperature (red), salinity (magenta), DIC (blue), and TA (yellow) to the observed carbon system gradients. The residual difference between the observed and calculated contributions is shown in cyan.

and orientation (Fig. 9). The Protected Middle and Protected Inside sites had significantly higher $\Omega_{\mathrm{Ar}}$ than the other four sites (except in the pairwise test between Protected Middle and Exposed Middle), which further highlights the clustering of the Protected Middle and Protected Inside sites relative to the other sites (Fig. 9). There were no significant siteto-site differences in surface $\Omega_{\mathrm{Ar}}$ values, indicating greater homogeneity at the surface. Not only were there significant differences in bottom water $\Omega_{\mathrm{Ar}}$, but the bottom waters were spatially decoupled as well. Throughout the year, bottom $\Omega_{\mathrm{Ar}}$ measurements from Protected Inside and Protected Middle were far less correlated with measurements from the deeper and more exposed sites, as compared to the correlations among the deeper, more exposed sites (Fig. 10). In contrast, the surface $\Omega_{\mathrm{Ar}}$ was highly correlated between all six sites (Fig. 10). The bottom water decoupling and surface water coupling were largely maintained during periods of both strong and weak upwelling (Fig. S8).

\section{Discussion}

This study demonstrates strong spatial and temporal variability in $\mathrm{CO}_{2}$ system chemistry within a central California kelp forest using nearly 800 DIC and TA observations that ranged across six sites, multiple depths, and spanned a period of 14 months. This data set represents one of the largest multiparameter $\mathrm{CO}_{2}$ system data sets completed in a kelp forest. Our spatially expansive sampling captured larger $\mathrm{pH}$ ranges than in many of the southern California pH studies. Our calculated range in $\mathrm{pH}$ of 7.7-8.33 was larger than the range observed in kelp forests from single $\mathrm{pH}$ sensors in the Channel Islands (Kapsenberg and Hofmann, 2016; 7.88-8.12), the La Jolla kelp forest (Takeshita et al., 2015; 7.78-8.12), and the Santa Barbara Channel (Hofmann et al., 2011; 7.78.25 ). Our $\mathrm{pH}$ range was slightly smaller than the range of $\sim 7.65-8.39$ observed by Frieder et al. (2012) in the La Jolla kelp forest using a network of $\mathrm{pH}$ sensors, although the high temporal resolution of the sensors captured event-scale variability that would likely be missed by the weekly sampling alone in our study. We now consider the physical and biological drivers of our observed variability and the implications of our work for understanding kelp forests in an era of global change.

\subsection{Mechanisms of observed variability}

Co-variation of water column structure and kelp canopy biomass provided evidence for the strong influence of regional-scale upwelling processes on the seasonal cycle of the kelp canopy (Fig. 2a). Bottom water advection during upwelling season introduces nutrients into the kelp forest, resulting in increased kelp growth and canopy biomass (Jackson, 1977). Unlike in southern California, where upwelling and canopy biomass are not tightly coupled, central California features very strong coupling between upwelling and kelp growth (Bell et al., 2015b). This strong co-variation provides support for asserting the role of both physical and biological drivers of kelp forest biogeochemistry.

During periods of strong upwelling, water column stratification increased (Fig. 2b) due to intrusion of cold, high-DIC bottom water (Figs. 3 and 8) into the deeper sites. Once bottom water was introduced to the deeper sites, it was more easily exchanged with kelp forest bottom waters on the exposed side than on the protected side. Bottom water velocities from July to December 2013, when data were available within the kelp forest on both the protected and exposed sides, revealed larger velocity variability on the exposed side 

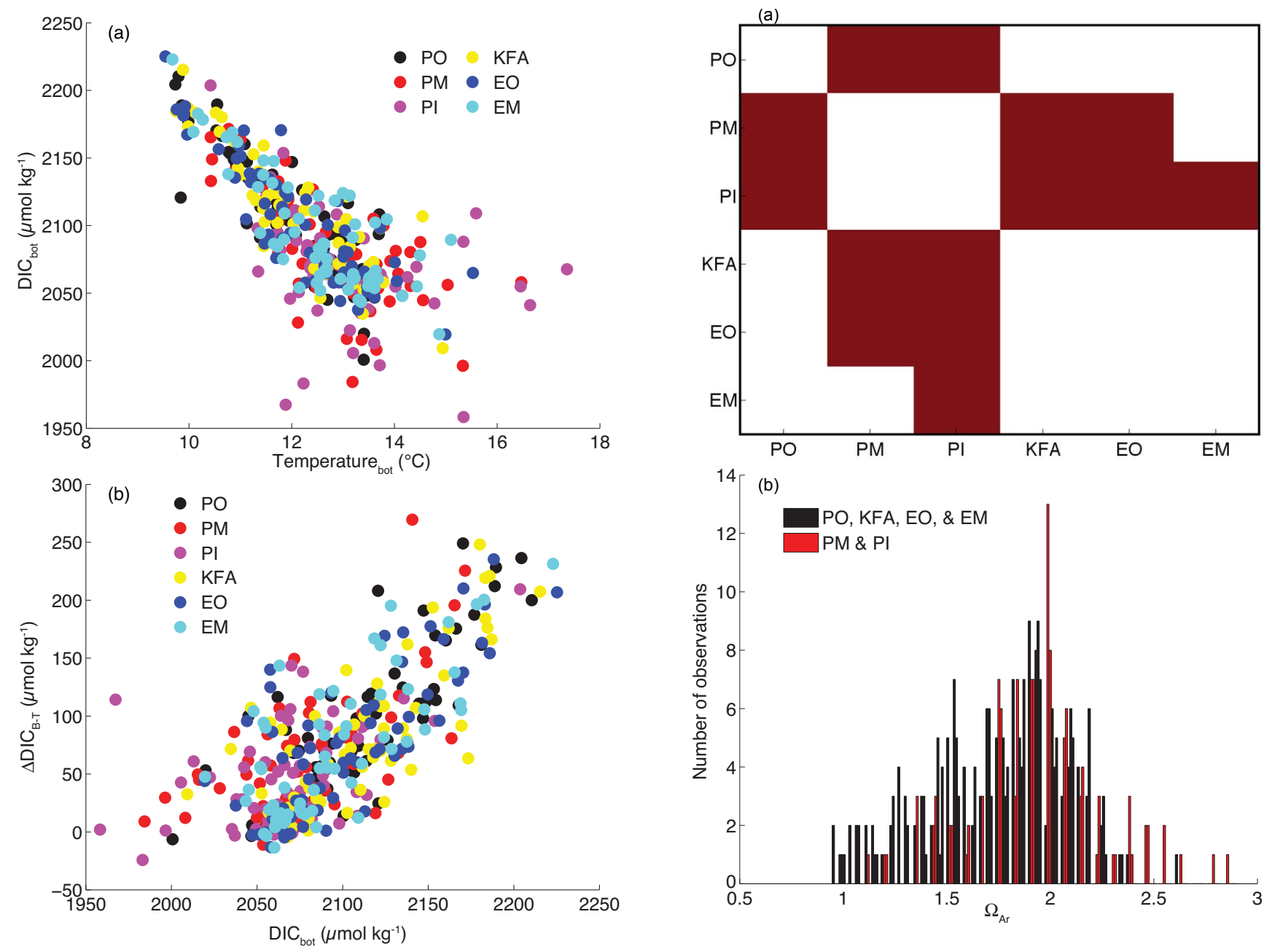

Figure 8. (a) Bottom DIC-bottom temperature relationships for all six sites and (b) bottom-to-surface DIC gradients as a function of bottom DIC concentrations.

than on the protected side (Fig. 11). The exposed side featured stronger downcoast (negative alongshore) and onshore (negative cross-shore) flow than did the protected side, which increased the exchange between offshore waters and the exposed side more so than on the protected side. Further physical oceanographic studies should ascertain the mechanisms responsible for the enhanced bottom water exchange on the exposed side relative to the protected side. We also recognize that higher-frequency water sampling may have captured the biogeochemical signature of occasional bottom water advection into the shallower sites that was missed through weekly sampling alone.

In light of all the evidence for the role of physical processes in shaping the biogeochemistry of the kelp forest, we emphasize that photosynthesis still played an important role in shaping the carbon system variability in the surface waters. Surface water $p \mathrm{CO}_{2}$ remained undersaturated with respect to the atmosphere starting at the beginning of upwelling

Figure 9. (a) Results of site-to-site bottom $\Omega_{\mathrm{Ar}}$ Wilcoxon rank sum test. Abbreviations on the sides refer to the six sites. Colored patches indicate significantly different $(p<0.05)$ bottom $\Omega_{\mathrm{Ar}}$ between the two sites. (b) Histogram of bottom $\Omega_{\mathrm{Ar}}$ values grouping Protected Middle and Inside (red) against the four deeper sites (black). Histogram excludes measurements from July and August 2013, when samples were not all collected on same day.

season and persisted throughout the summer months (Fig. 5). The persistent undersaturation of surface waters is strong evidence of photosynthesis' role in contributing to biogeochemical variability in spring and summer months, particularly in the surface waters where the bulk of kelp biomass resides. We note that photosynthesis was likely occurring throughout most of the water column due to understory algae, but the vertical resolution of our sampling ( $1 \mathrm{~m}$ a.b. and $1 \mathrm{~m}$ b.s.) prohibits us from being able to quantify this contribution. More vertically resolved measurements are needed to understand the role of understory production in the kelp forest.

Although we are unable to quantitatively partition the photosynthetic activity between kelp and phytoplankton in the kelp forest, we note that surface $p \mathrm{CO}_{2}$ was undersaturated as early as February 2014 (Fig. 5b), when kelp canopy biomass 


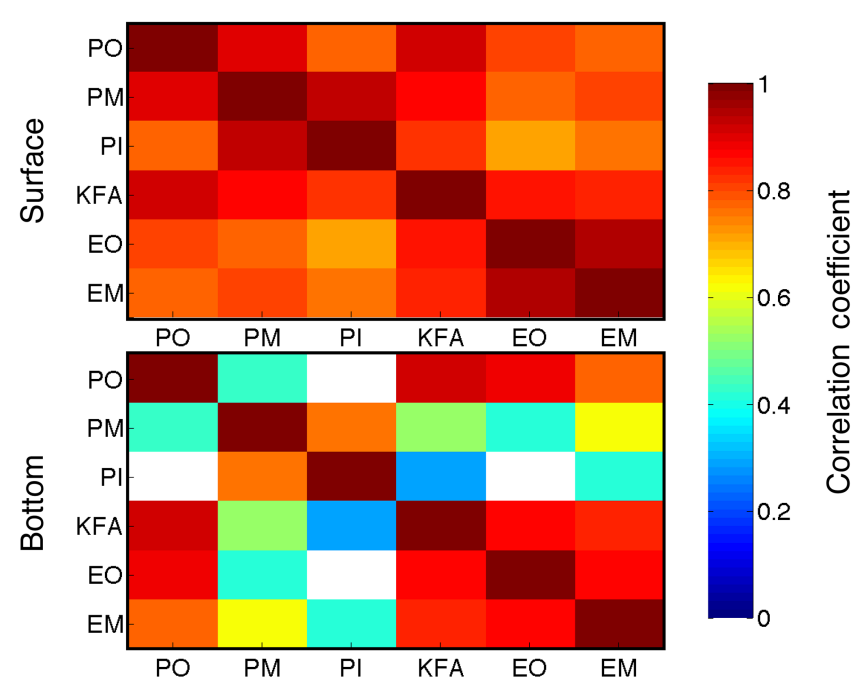

Figure 10. Correlation heat maps of $\Omega_{\mathrm{Ar}}$ for the full year. Top panel shows correlations between surface sites, and the bottom panel shows correlations between bottom sites. Site names are abbreviated on both panels and correspond to the order presented in the legend of Fig. 9a. Blank spaces show statistically insignificant $(p>0.05)$ correlations.
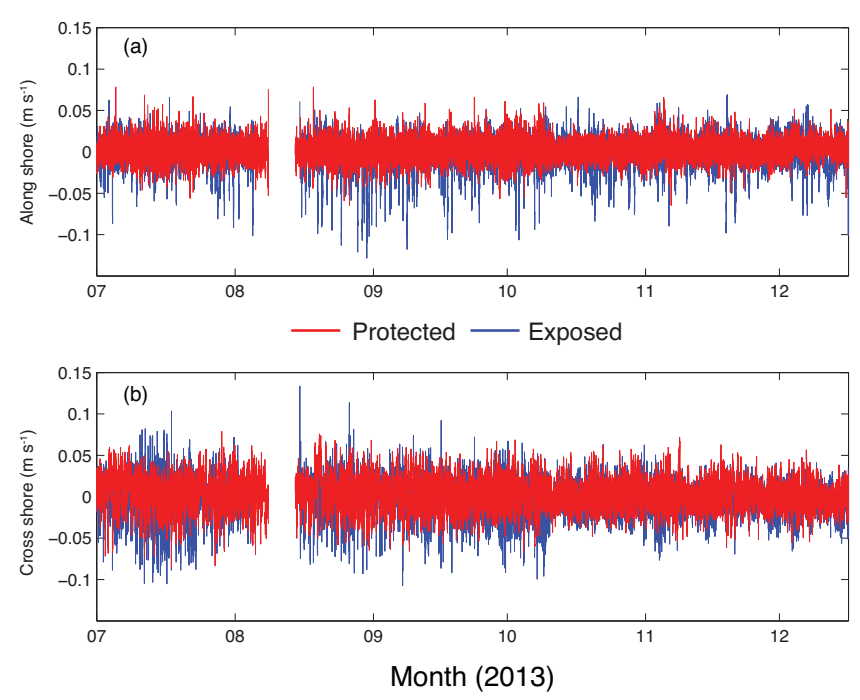

Figure 11. Depth-averaged (0-5 m a.b.) bottom (a) alongshore and (b) cross-shore velocities from the Protected Mid and Exposed Mid acoustic Doppler current profilers collected from July to December 2013. Positive alongshore velocity is $40^{\circ}$ counterclockwise from north at Protected Mid and $13^{\circ}$ counterclockwise from north at Exposed Mid. Positive cross-shore velocities are $90^{\circ}$ clockwise from positive alongshore velocities (offshore).

was near minimum values (Fig. 2a). We hypothesize that early season $\mathrm{CO}_{2}$ uptake was controlled by the phytoplankton community in the absence of kelp. Once the kelp canopy was established several months later, the kelp played an important biogeochemical role both through direct photosyn- thetic uptake as well as through reduction of water velocity within the kelp forest (Rosman et al., 2007), which allowed greater biogeochemical modification of surface water chemistry through phytoplankton and kelp metabolism. This hypothesis is testable using offshore sampling sites outside the influence of the kelp forest to better quantify the phytoplankton and kelp community contributions to the observed biogeochemical variability. However, our offshore sites were only tens of meters outside of the kelp. Therefore, it is not surprising that we are unable to distinguish surface waters from within the kelp forest from those just outside the kelp. Future sampling efforts would benefit from utilizing offshore sites further from the influence of the kelp, as well as phytoplankton-specific tracers, such as silica (Jackson, 1977), in order to better partition the biogeochemical contributions from various functional groups within the kelp forest community.

In contrast to the evidence for surface photosynthesis, we do not see biogeochemical evidence for significant calcification within the kelp forest. Benthic calcification would have depleted TA in the bottom waters relative to the surface, yet we see no consistent pattern in the vertical TA gradients (Fig. 6b). The lack of TA gradients suggests that the biogeochemical signature of calcification in the bottom waters of the kelp forest was small relative to bottom water exchange in the kelp forest.

\subsection{Implications for understanding kelp forest ecosystems in an era of global change}

Our data provide critical biogeochemical baselines to assess kelp forest responses to local and global stressors and further highlight the necessity of long-term, spatially expansive sampling for gaining insights into the patterns and controls on kelp forest biogeochemistry. Kelp forests are spatially and temporally dynamic environments generally found along upwelling margins, so any assessment of their biogeochemical variability must account for the variability in their seasonalto-interannual physical (Bograd et al., 2009; Checkley and Barth, 2009) and biological controls (Bell et al., 2015b). We have demonstrated how variations in these physical and biological controls in a central California kelp forest create biogeochemically heterogeneous environments. This creates the opportunity to do localized "space-for-time" experiments to understand benthic organismal and community response to high- $\mathrm{CO}_{2}$ seawater. In contrast to larger spacefor-time experiments (Hofmann et al., 2014), a single kelp forest may be sufficient for replicating the geochemical gradients expected between current conditions and future conditions under ocean acidification. These localized space-fortime experiments could be conducted in small environments (hundreds of meters, not hundreds of kilometers) with nearidentical biological assemblages and for a fraction of the cost and effort. Combining transplant experiments with observational work could leverage the biogeochemical differences 
between areas of a kelp forest to yield important insights into the adaptive potential of benthic community members under the combined stresses of global change.

Aqueous $\mathrm{CO}_{2}$ variability typically does not occur in isolation of other biogeochemical and environmental changes. Although we do not have the $\mathrm{O}_{2}$ measurements to accompany our carbon system time series, co-variation of $\mathrm{CO}_{2}$ and $\mathrm{O}_{2}$ has been well documented in California's coastal ecosystems (Booth et al., 2012; Frieder et al., 2012; Takeshita et al., 2015), and frequent episodic hypoxia has been documented near our study site (Booth et al., 2012). While a large component of this variation is naturally occurring along upwelling margins, low- $\mathrm{O}_{2}$, high- $\mathrm{CO}_{2}$ events are predicted to increase in frequency in the future due to oxygen minimum zone expansion (Bograd et al., 2008; Booth et al., 2014; Stramma et al., 2010) and increases in upwelling favorable winds (Bakun, 1990; Sydeman et al., 2014). Understanding the co-variation, or lack thereof, between critical environmental parameters (e.g., temperature, $\mathrm{CO}_{2}$ system variables, and $\mathrm{O}_{2}$ ) through long-term spatially expansive measurements is necessary to define the range and timescales of environmental conditions experienced by kelp forest inhabitants. Quantifying these environmental conditions can inform the design of more realistic laboratory experiments, featuring proper ranges and timescales of biogeochemical and thermal variability as opposed to chemostatic conditions (Reum et al., 2015). More realistic experimental conditions will yield additional insights into organismal and community response to climate change and OA.

Our data demonstrate that, despite the strong influence of physical processes, primary production can alter local biogeochemistry. Understanding the role of foundation species, such as giant kelp, in creating biogeochemical refugia both through metabolic activity and alteration of the hydrodynamic regime within the kelp forest via increased residence time (Rosman et al., 2007) warrants further attention in an acidifying ocean, as they present potential to mitigate some stress effects of low- $\mathrm{O}_{2}$, high- $\mathrm{CO}_{2}$ water. The combination of physical and biological processes may create natural refugia for certain sensitive organisms or, conversely, create particularly stressful conditions for others. Organisms that can confine themselves to the upper water column may be able to use the locally created biogeochemical refuge to avoid low $\mathrm{pH}$, whereas organisms that must use the entire water column will experience large ranges in carbonate chemistry $\left(\mathrm{pH}, p \mathrm{CO}_{2}\right.$, and $\Omega_{\mathrm{Ar}}$ ) that will only grow larger with continued acidification.

In order to effectively manage critical coastal ecosystems in the face of climate change and OA, resource managers require both monitoring data and a process-based understanding of biogeochemical variability in order to identify changing environmental conditions and forecast ecosystem responses in kelp forests (Boehm et al., 2015). Such understanding is currently lacking. Along the US west coast, states currently use decades-old water quality criteria for assessing
$\mathrm{pH}$, including that the $\mathrm{pH}$ should not drop below 6.5 and/or that it should not deviate more than 0.2 units from natural conditions (Weisberg et al., 2016). Yet we have demonstrated changes up to $0.5 \mathrm{pH}$ units within a single kelp forest in just $15 \mathrm{~m}$ depth. Additional observational studies may prove useful in helping us refine our understanding of coastal water quality away from static indicators and towards a more dynamic understanding of the ranges and controls on coastal water quality in order to better differentiate natural and anthropogenic effects, as has been demonstrated for dissolved oxygen (Booth et al., 2014). We recommend that regulatory agencies revise existing regulations to incorporate this understanding of natural variability in carbonate chemistry into their regulatory frameworks, as well as to expand the suite of carbonate chemistry water quality variables beyond $\mathrm{pH}$ alone (Weisberg et al., 2016). Developing stronger biological criteria for carbonate chemistry ranges and variability deemed necessary to preserve critical marine living resources would help align scientific and management priorities by focusing research efforts on quantifying these acceptable ranges of conditions (Chan et al., 2016; Weisberg et al., 2016).

Comprehensive, spatially expansive monitoring is fundamental to characterizing the ranges and timescales of carbonate system variability in highly productive coastal ecosystems, such as kelp forests. Maintaining monitoring networks along coastal ecosystems is a crucial step to developing an understanding of natural vs. anthropogenic influences in the coastal zone in support management and regulatory efforts (Strong et al., 2014). Recent advances in sensor technology, such as the SeapHOx (Bresnahan et al., 2014), may make monitoring far less laborious than the data collection efforts in this study. However, we strongly recommend that monitoring programs measure at least two carbonate system parameters (TA, DIC, $\mathrm{pH}, p \mathrm{CO}_{2}$ ) so as to fully constrain the carbonate system (McLaughlin et al., 2015), with a goal of measuring three or more parameters to over-constrain the system. Coupling SeapHOx sensors to autonomous $p \mathrm{CO}_{2}$ (as discussed in Martz et al., 2015) or newly developed autonomous TA sensors (Spaulding et al., 2014) may accomplish this task. Integrating observations from individual sites along the California coast into larger coordinated networks, such as the California Current Acidification Network, will provide a more complete perspective on the spatial and temporal variability of the aqueous $\mathrm{CO}_{2}$ system and its controls (Chan et al., 2016; McLaughlin et al., 2015).

Long-term observational data sets are also crucial for improving our process-based understanding of coastal ocean biogeochemistry. Data from studies such as these can be used to parameterize the process-based hydrodynamicbiogeochemical models that are needed to predict coastal ecosystem responses to climate change and ocean acidification (Boehm et al., 2015; McLaughlin et al., 2015). These models can help identify climate change and/or ocean acidification hotspots along coastal ecosystems in the future and help marine living resource managers with scenario planning 
so that they can direct resources accordingly (Strong et al., 2014). Similarly, marine resource managers must consider the biogeochemical implications of any management activities, such as kelp harvesting, which alter kelp canopy density. We have shown considerable $\mathrm{CO}_{2}$ uptake at our study site during periods of high kelp canopy cover. While we were not able to directly attribute the $\mathrm{CO}_{2}$ uptake to Macrocystis pyrifera, the direct and indirect effects of the kelp canopy are likely to increase vertical gradients in water chemistry and therefore activities that decrease canopy density are likely to reduce gradients in the water column.

Kelp forest ecology has long been a focal point for marine ecologists. This study complements the long history of kelp forest community (Dayton, 1985; Graham et al., 2007) and disturbance ecology (Edwards, 2004; Edwards and Estes, 2006) by highlighting the dynamic biogeochemistry of kelp forests over an annual cycle. The few existing biogeochemical studies of Macrocystis pyrifera-dominated kelp forest along the California coast have thus far occurred in southern California (Frieder et al., 2012; Kapsenberg and Hofmann, 2016; Takeshita et al., 2015). This study expands on the southern California studies by adding the first fully resolving $\mathrm{CO}_{2}$ system chemistry study in a central California kelp forest where seasonality is relatively stronger and kelp cover is more variable (Bell et al., 2015b; Checkley and Barth, 2009; Reed et al., 2011).

We hope that the large data set presented here motivates the inclusion of biogeochemistry as a new approach to understand kelp forest ecosystem function and the feedbacks between biology, chemistry, and physics in these dynamic systems. We note that this study would not have been possible without a large and concerted field effort to establish a spatially expansive sampling program that ranged over gradients in kelp density and wave exposure. Yet this sampling program was necessary to generate insights into the relevant scales of kelp forest biogeochemical variability presented in this study, variability that could not be discerned from a single sampling point or sensor alone. We advocate for monitoring efforts to extend beyond single-site measurements within a kelp forest. Doing so will enhance our understanding of the biological and physical mechanisms giving rise to the observed biogeochemical variability - information crucial to accurately predicting the response of kelp forest ecosystems to global change.

\section{Data availability}

Data presented in this study are available in the Supplement.

\section{Information about the Supplement}

Supporting figures and tables can be found in the Supplement to this study.

\section{The Supplement related to this article is available online at doi:10.5194/bg-14-31-2017-supplement.}

Competing interests. The authors declare that they have no conflict of interest.

Acknowledgements. We thank two anonymous reviewers for their thoughtful reviews that improved this paper. Heidi Hirsh and Hans DeJong provided laboratory assistance. Kristin Elsmore, Ana Guerra, Jesse Lafian, Diana LaScala-Gruenewald, Lupita RuizJones, Drew Simon, and Tim White provided field assistance. Fio Micheli provided laboratory facilities to use in support of this project. Bill Gilly provided the use of the CTD in this study. Conversations with Andreas Andersson, Kevin Arrigo, Tyler Cyronak, Stephen Monismith, and Yui Takeshita improved this study. The School of Earth, Energy, and Environmental Sciences and the Marine Life Observatory of Stanford University supported this project. David A. Koweek and Paul R. Leary were supported by NSF Graduate Research Fellowships (DGE-114747). Kerry J. Nickols was supported by the Marine Life Observatory of Hopkins Marine Station. Steve Y. Litvin was supported by the Marine Life Observatory of Hopkins Marine Station and the NSF Ocean Acidification Program (OCE-1416934). Tom W. Bell was supported through the NASA Earth and Space Science Fellowship. The satellite-derived canopy biomass estimates were supported by NSF through its support of the Santa Barbara Coastal LTER (OCE-0620276 and OCE-1232779). This research was conducted under Monterey Bay National Marine Sanctuary permit number MBNMS-2010-002-A2.

Edited by: L. Cotrim da Cunha

Reviewed by: two anonymous referees

\section{References}

Bakun, A.: Global climate change and intensification of coastal ocean upwelling, Science, 247, 198-201, doi:10.1126/science.247.4939.198, 1990.

Bell, T. W., Cavanaugh, K. C., Reed, D. C., and Siegel, D. A.: Geographical variability in the controls of giant kelp biomass dynamics, J. Biogeogr., 42, 2010-2021, doi:10.1111/jbi.12550, 2015a.

Bell, T. W., Cavanaugh, K. C., and Siegel, D. A.: Remote monitoring of giant kelp biomass and physiological condition: An evaluation of the potential for the Hyperspectral Infrared Imager (HyspIRI) mission, Remote Sens. Environ., 167, 218-228, doi:10.1016/j.rse.2015.05.003, 2015 b. 
Boehm, A. B., Jacobson, M. Z., O’Donnell, M. J., Sutula, M., Wakefield, W. W., Weisberg, S. B., and Whiteman, E.: Ocean acidification science needs for natural resource managers of the North American west coast, Oceanography, 28, 170-181, 2015.

Bograd, S. J., Castro, C. G., Di Lorenzo, E., Palacios, D. M., Bailey, H., Gilly, W., and Chavez, F. P.: Oxygen declines and the shoaling of the hypoxic boundary in the California Current, Geophys. Res. Lett., 35, 1-6, doi:10.1029/2008GL034185, 2008.

Bograd, S. J., Schroeder, I., Sarkar, N., Qiu, X., Sydeman, W. J., and Schwing, F. B.: Phenology of coastal upwelling in the California Current, Geophys. Res. Lett., 36, 1-5, doi:10.1029/2008GL035933, 2009.

Booth, J. A. T., McPhee-Shaw, E. E., Chua, P., Kingsley, E., Denny, M., Phillips, R., Bograd, S. J., Zeidberg, L. D., and Gilly, W. F.: Natural intrusions of hypoxic, low $\mathrm{pH}$ water into nearshore marine environments on the California coast, Cont. Shelf Res., 45, 108-115, doi:10.1016/j.csr.2012.06.009, 2012.

Booth, J. A. T., Woodson, C. B., Sutula, M., Micheli, F., Weisberg, S. B., Bograd, S. J., Steele, A., Schoen, J., and Crowder, L. B.: Patterns and potential drivers of declining oxygen content along the southern California coast, Limnol. Oceanogr., 59, 1127-1138, doi:10.4319/lo.2014.59.4.0000, 2014.

Bresnahan, P. J., Martz, T. R., Takeshita, Y., Johnson, K. S., and LaShomb, M.: Best practices for autonomous measurement of seawater $\mathrm{pH}$ with the Honeywell Durafet, Methods Oceanogr., 9, 44-60, doi:10.1016/j.mio.2014.08.003, 2014.

Brzezinski, M. A., Jones, J. L., Bidle, K. D., and Azam, F.: The balance between silica production and silica dissolution in the sea: insights from Monterey Bay, California applied to the global data set, Limnol. Oceanogr., 48, 1846-1854, doi:10.4319/lo.2003.48.5.1846, 2003.

Cavanaugh, K. C., Siegel, D., Reed, D., and Dennison, P.: Environmental controls of giant-kelp biomass in the Santa Barbara Channel, California, Mar. Ecol.-Prog. Ser., 429, 1-17, doi:10.3354/meps09141, 2011.

Chan, F., Boehm, A. B., Barth, J. A., Chornesky, E. A., Dickson, A. G., Feely, R. A., Hales, B., Hill, T. M., Hofmann, G. E., Ianson, D., Klinger, T., Largier, J. L., Newton, J. A., Pedersen, T., Somero, G. N., Sutula, M., Wakefield, W. W., Waldbusser, G. G., Weisberg, S. B., and Whiteman, E.: The West Coast Ocean Acidification and Hypoxia Science Panel: Major Findings, Recommendations, and Actions, Oakland, California, 2016.

Checkley, D. M. and Barth, J. A.: Patterns and processes in the California Current System, Prog. Oceanogr., 83, 49-64, doi:10.1016/j.pocean.2009.07.028, 2009.

Dayton, P. K.: Ecology of Kelp Communities, Annu. Rev. Ecol. Syst., 16, 215-245, doi:10.1146/annurev.es.16.110185.001243, 1985.

Delille, B., Delille, D., Fiala, M., Prevost, C., and Frankignoulle, M.: Seasonal changes of $p \mathrm{CO}_{2}$ over a subantarctic Macrocystis kelp bed, Polar Biol., 23, 706-716, 2000.b

Delille, B., Borges, A. V., and Delille, D.: Influence of giant kelp beds (Macrocystis pyrifera) on diel cycles of $p \mathrm{CO}_{2}$ and DIC in the sub-Antarctic coastal area, Estuar. Coast. Shelf Sci., 81, 114 122, doi:10.1016/j.ecss.2008.10.004, 2009.

Dickson, A. G.: Standard potential of the reaction: $\mathrm{AgCl}(\mathrm{s})+1 / 2 \mathrm{H}_{2}(\mathrm{~g})=\mathrm{Ag}(\mathrm{s})+\mathrm{HCl}(\mathrm{aq})$, and the standard acidity constant of the ion $\mathrm{HSO}_{4}^{-}$in synthetic sea water from
273.15 to $318.15 \mathrm{~K}$, J. Chem. Thermodyn., 22, 113-127, doi:10.1016/0021-9614(90)90074-Z, 1990.

Dickson, A. G. and Millero, F. J.: A comparison of the equilibrium constants for the dissociation of carbonic acid in seawater media, Deep-Sea Res. Pt. A, 34, 1733-1743, doi:10.1016/01980149(87)90021-5, 1987.

Dickson, A. G., Afghan, J. D., and Anderson, G. C.: Reference materials for oceanic $\mathrm{CO}_{2}$ analysis: a method for the certification of total alkalinity, Mar. Chem., 80 185-197, doi:10.1016/S03044203(02)00133-0, 2003.

Edwards, M. S.: Estimating scale-dependency in disturbance impacts: El Ninos and giant kelp forests in the northeast Pacific, Oecologia, 138, 436-447, doi:10.1007/s00442-003-1452-8, 2004.

Edwards, M. S. and Estes, J. A.: Catastrophe, recovery and range limitation in NE Pacific kelp forests: A large-scale perspective, Mar. Ecol.-Prog. Ser., 320, 79-87, doi:10.3354/meps320079, 2006.

Frieder, C. A., Nam, S. H., Martz, T. R., and Levin, L. A.: High temporal and spatial variability of dissolved oxygen and $\mathrm{pH}$ in a nearshore California kelp forest, Biogeosciences, 9, 3917-3930, doi:10.5194/bg-9-3917-2012, 2012.

Graham, M. H., Vásquez, J. A., and Buschmann, A. H.: Global ecology of the giant kelp Macrocystis: from ecotypes to ecosystems, in: Oceanography and Marine Biology: An Annual Review, edited by: Gibson, R. N., Atkinson, R. J., and Gordon, J. D. M., Taylor and Francis, 45, 39-88, 2007.

Hauri, C., Gruber, N., Vogt, M., Doney, S. C., Feely, R. A., Lachkar, Z., Leinweber, A., McDonnell, A. M. P., and Munnich, M.: Spatiotemporal variability and long-term trends of ocean acidification in the California Current System, Biogeosciences, 10, 193 216, doi:10.5194/bg-10-193-2013, 2013.

Hofmann, G. E., Smith, J. E., Johnson, K. S., Send, U., Levin, L. A., Micheli, F., Paytan, A., Price, N. N., Peterson, B., Takeshita, Y., Matson, P. G., Crook, E. D., Kroeker, K. J., Gambi, M. C., Rivest, E. B., Frieder, C. A., Yu, P. C., and Martz, T. R.: High-frequency dynamics of ocean $\mathrm{pH}$ : a multi-ecosystem comparison, PLoS One, 6, 1-11, doi:10.1371/journal.pone.0028983, 2011.

Hofmann, G. E., Evans, T. G., Kelly, M. W., Padilla-Gamiño, J. L., Blanchette, C. A., Washburn, L., Chan, F., McManus, M. A., Menge, B. A., Gaylord, B., Hill, T. M., Sanford, E., Lavigne, M., Rose, J. M., Kapsenberg, L., and Dutton, J. M.: Exploring local adaptation and the ocean acidification seascape-studies in the California Current Large Marine Ecosystem, Biogeosciences, 11, 1053-1064, doi:10.5194/bg-11-1053-2014, 2014.

Jackson, G. A.: Nutrients and production of giant kelp, Macrocystis pyrifera, off southern California, Limnol. Oceanogr., 22, 979995, 1977.

Kapsenberg, L. and Hofmann, G. E.: Ocean pH time-series and drivers of variability along the northern Channel Islands, California, USA, Limnol. Oceanogr., 61, 953-968, doi:10.1002/lno.10264, 2016.

Long, M. C., Dunbar, R. B., Tortell, P. D., Smith, W. O., Mucciarone, D. A., and DiTullio, G. R.: Vertical structure, seasonal drawdown, and net community production in the Ross Sea, Antarctica, J. Geophys. Res.-Oceans, 116, 1-19, doi:10.1029/2009JC005954, 2011.

Lovers Point-Julia Platt State Marine Reserve, California Department of Fish and Wildlife, 2016. 
Mann, K. H.: Ecology of Coastal Waters: A Systems Approach, University of California Press, 1982.

Martz, T. R., Daly, K. L., Byrne, R. H., Stillman, J. H., and Turk, D.: Technology for ocean acidification research needs: Needs and availability, Oceanography, 28, 40-47, doi:10.5670/oceanog.2015.30, 2015.

McLaughlin, K., Weisberg, S. B., Dickson, A. G., Hofmann, G. E., Newton, J. A., Aseltine-Neilson, D., Barton, A., Cudd, S., Feely, R. A., Jefferds, I. W., Jewett, E. B., King, T., Langdon, C. J., McAfee, S., Pleschner-Steele, D., and Steele, B.: Core principles of the California Current Acidification Network: Linking chemistry, physics, and ecological effects, Oceanography, 28, 160 169, doi:10.5670/oceanog.2015.39, 2015.

Mehrbach, C., Culberson, C. H., Hawley, J. E., and Pytkowicz, R. M.: Measurement of the apparent dissociation constants of carbonic acid in seawater at atmospheric pressure, Limnol. Oceanogr., 18, 897-907, doi:10.4319/lo.1973.18.6.0897, 1973.

Reed, D. C., Rassweiler, A., Carr, M. H., Cavanaugh, K. C., Malone, D. P., and Siegel, D. A.: Wave disturbance overwhelms top-down and bottom-up control of primary production in California kelp forests, Ecology, 92, 2108-2116, 2011.

Reum, J. C., Alin, S. R., Harvey, C. J., Bednaršek, N., Evans, W., Feely, R. A., Hales, B., Lucey, N., Mathis, J. T., McElhany, P., Newton, J., and Sabine, C. L.: Interpretation and design of ocean acidification experiments in upwelling systems in the context of carbonate chemistry co-variation with temperature and oxygen, ICES J. Mar. Sci., 73, 582-595, doi:10.1093/icesjms/fst176, 2015.

Roberts, D. A., Gardner, M., Church, R., Ustin, S., Scheer, G., and Green, R. O.: Mapping chaparral in the Santa Monica Mountains using multiple endmember spectral mixture models, Remote Sens. Environ., 65, 267-279, doi:10.1016/S00344257(98)00037-6, 1998.

Rosman, J. H., Koseff, J. R., Monismith, S. G., and Grover, J.: A field investigation into the effects of a kelp forest (Macrocystis pyrifera) on coastal hydrodynamics and transport, J. Geophys. Res.-Oceans, 112, 1-16, doi:10.1029/2005JC003430, 2007.

Sabine, C. L., Feely, R. A., Gruber, N., Key, R. M., Lee, K., Bullister, J. L., Wanninkhof, R., Wong, C. S., Wallace, D. W. R., Tilbrook, B., Millero, F. J., Peng, T. H., Kozyr, A., Ono, T., and Rios, A. F.: The oceanic sink for anthropogenic $\mathrm{CO}_{2}$, Science, 305, 367-71, doi:10.1126/science.1097403, 2004.

Spaulding, R. S., DeGrandpre, M. D., Beck, J. C., Hart, R. D., Peterson, B., DeCarlo, E. H., Drupp, P. S., and Hammar, T. R.: Autonomous in situ measurements of seawater alkalinity., Environ. Sci. Technol., 48, 9573-9581, doi:10.1021/es501615x, 2014.
Steneck, R. S., Graham, M. H., Bourque, B. J., Corbett, D., Erlandson, J. M., Estes, J. A., and Tegner, M. J.: Kelp forest ecosystems: biodiversity, stability, resilience and future, Environ. Conserv., 29, 436-459, doi:10.1017/S0376892902000322, 2002.

Stramma, L., Schmidtko, S., Levin, L. A., and Johnson, G. C.: Ocean oxygen minima expansions and their biological impacts, Deep-Sea Res. Pt. I, 57, 587-595, doi:10.1016/j.dsr.2010.01.005, 2010.

Strong, A. L., Kroeker, K. J., Teneva, L. T., Mease, L. A., and Kelly, R. P.: Ocean acidification 2.0: managing our changing coastal ocean chemistry, Bioscience, 64, 581-592, doi:10.1093/biosci/biu072, 2014.

Sydeman, W. J., Garcia-Reyes, M., Schoeman, D. S., Rykaczewski, R. R., Thompson, S. A., Black, B. A., and Bograd, S. J.: Climate change and wind intensification in coastal upwelling ecosystems, Science, 345, 77-80, doi:10.1126/science.1251635, 2014.

Takeshita, Y., Frieder, C. A., Martz, T. R., Ballard, J. R., Feely, R. A., Kram, S., Nam, S., Navarro, M. O., Price, N. N., and Smith, J. E.: Including high-frequency variability in coastal ocean acidification projections, Biogeosciences, 12, 5853-5870, doi:10.5194/bg-12-5853-2015, 2015.

van Heuven, S., Pierrot, D., Rae, J., Lewis, E., and Wallace, D. W. R.: MATLAB Program Developed for $\mathrm{CO}_{2}$ System Calculations, Oak Ridge National Laboratory, US Department of Energy, Oak Ridge, Tennessee, 2011.

Walter, R. K., Woodson, C. B., Leary, P. R., and Monismith, S. G.: Connecting wind-drien upwelling and offshore stratification to nearshore internal bores and oxygen variability, J. Geophys. Res.-Ocean., 119, 3517-3534, doi:10.1002/jgrc.20224, 2014.

Weisberg, S. B., Bednaršek, N., Feely, R. A., Chan, F., Boehm, A. B., Sutula, M., Ruesink, J. L., Hales, B., Largier, J. L., and Newton, J. A.: Water quality criteria for an acidifying ocean: Challenges and opportunities for improvement, Ocean Coast. Manag., 126, 31-41, doi:10.1016/j.ocecoaman.2016.03.010, 2016.

Woodson, C. B.: Spatiotemporal Variation in Cross-Shelf Exchange across the Inner Shelf of Monterey Bay, California, J. Phys. Oceanogr., 43, 1648-1665, doi:10.1175/JPO-D-11-0185.1, 2013. 